\title{
MANAGEMENT OF TWO CASES OF DESQUAMATIVE GINGIVITIS WITH CLOBETASOL AND CALENDULA OFFICINALIS GEL
}

\author{
Maria Angela Naval Machado ${ }^{a *}$, Cintia Mussi Milani Contar ${ }^{\mathrm{b}}$, Jean Ayres Brustolimc, \\ Lisiane Candido ${ }^{c}$, Luciana Reis Azevedo-Alanis ${ }^{c}$, Ana Maria Trindade Gregio ${ }^{c}$, \\ Paula Cristina Trevilatto ${ }^{c}$, Antonio Adilson Soares de Lima ${ }^{\mathrm{a}}$
}

\begin{abstract}
a Department of Stomatology, Faculty of Dentistry, Universidade Federal do Paraná, Av. Pref. Lothário Meissner 3400, CEP 80210-170, Curitiba, Paraná, Brasil

b School of Dentistry, Universidade Tuiuti do Paraná, Rua Sidney Antonio Rangel Santos 238, CEP:82010-330, Curitiba, Paraná, Brazil

c Center of Health and Biological Sciences, Pontifícia Universidade Católica do Paraná, Rua Imaculada Conceição 1135, CEP: 80215-901, Curitiba, Paraná, Brasil.
\end{abstract}

E-mail:man.machado@ufpr.br

Received: August 29, 2010; Accepted: November 10, 2010

Key Words: Lichen planus/Treatment/Clobetasol/Calendula

Background. The purpose of this paper is to describe two cases of desquamative gingivitis (DG) that were treated with a topic gel containing clobetasol propionate and Calendula officinalis $L$ in an acetate tray over two years.

Methods. Two patients with a diagnosis of lichen planus presenting as DG who had undergone previous treatments for this condition with no significant results, were treated by a handling gel containing clobetasol, nystatin, Calendula oficcinalis $L$ and pectin in custom trays.

Results. Both patients had remission of symptoms while using the trays and after they stopped the treatment, the symptomatic outbreaks were delayed and presented as less severe symptoms in the two years follow-up. The treatment is aimed primarily at reducing the length and severity of symptomatic outbreaks desquamative gingivitis

Conclusion. This handling gel using a tray may be an efficacious treatment of desquamative gingivitis.

\section{INTRODUCTION}

The oral lichen planus (OLP) is a chronic inflammatory mucocutaneous disease with uncertain etiology and auto-immune pathogenia ${ }^{1-3}$. The lesions are usually multiple and almost always have a bilateral symmetrical distribution, characterized by relapses and remissions periods $^{2-5}$.

OLP affects approximately $1 \%$ to $4 \%$ of the population, with a peak incidence in the $30-60$ years age ${ }^{5,7}$ and women are more commonly affected than man $^{2}$.

Most patients are usually asymptomatic, however burning sensation and pain interference with speaking and eating are common symptoms in the atrophic and erosive forms ${ }^{7-9}$. Spontaneous remission is rare and many lesions require treatment ${ }^{4}$. The most widely used agent in treatment are corticosteroids, which can be used topically, intralesionally or systemically ${ }^{4-7}$.

Erythematous or ulcerated lesions that affect the entire width of the attached gingiva cause a condition called desquamative gingivitis $(\mathrm{DG})^{2}$.

This article describes two cases of DG that were treated with handling gel containing clobetasol propionate, Calendula officinalis L, pectin and nystatin used in bleaching - like custom-fitted ethylene vinyl acetate tray. More than one-year follow up showed periodic recurrence, however with longer disease-free periods and less severe symptoms.

\section{Case 1}

A 40-year-old healthy white male was referred to the Stomatology Diagnosis Service at Pontificia Universidade Católica do Paraná with a chief complain of pain and associated soreness of the gingiva for about three years, with periods of exarcerbation and quiescence. Intraoral examination revealed erythemathous and diffuse desquamative lesions of the gingiva, which were generalized for all maxillar region, bilaterally (Fig. 1a,1b). The associated teeth had no mobility and no bleeding on probing, but a variable amount of dental biofilm was observed.

Based on the clinical features a diagnosis of atrophicerosive OLP was made. Incisional biopsy was performed and histopathological examination confirmed the diagnosis.

A prescription of a handling gel containing $0.05 \%$ clobetasol propionate, 3\% Calendula officinalis $\mathrm{L}$ extract, $100.000 \mathrm{IU} / \mathrm{ml}$ of nystatin and $5 \%$ pectin was done. A custom-fitted tray was made with a $1.5 \mathrm{~mm}$ thick ethylene vinyl acetate sheet, which covered the upper and lower dental arch. The patient was instructed to fill the tray with the gel and keep it in place for $15 \mathrm{~min}$, three times a day. He should refrain from eating and drinking for at least $30 \mathrm{~min}$ after application.

Following completion of 2-weeks treatment, substantial improvement was observed in the gingival lesions (Fig. 1c,1d). The patient reported reduction of pain. 

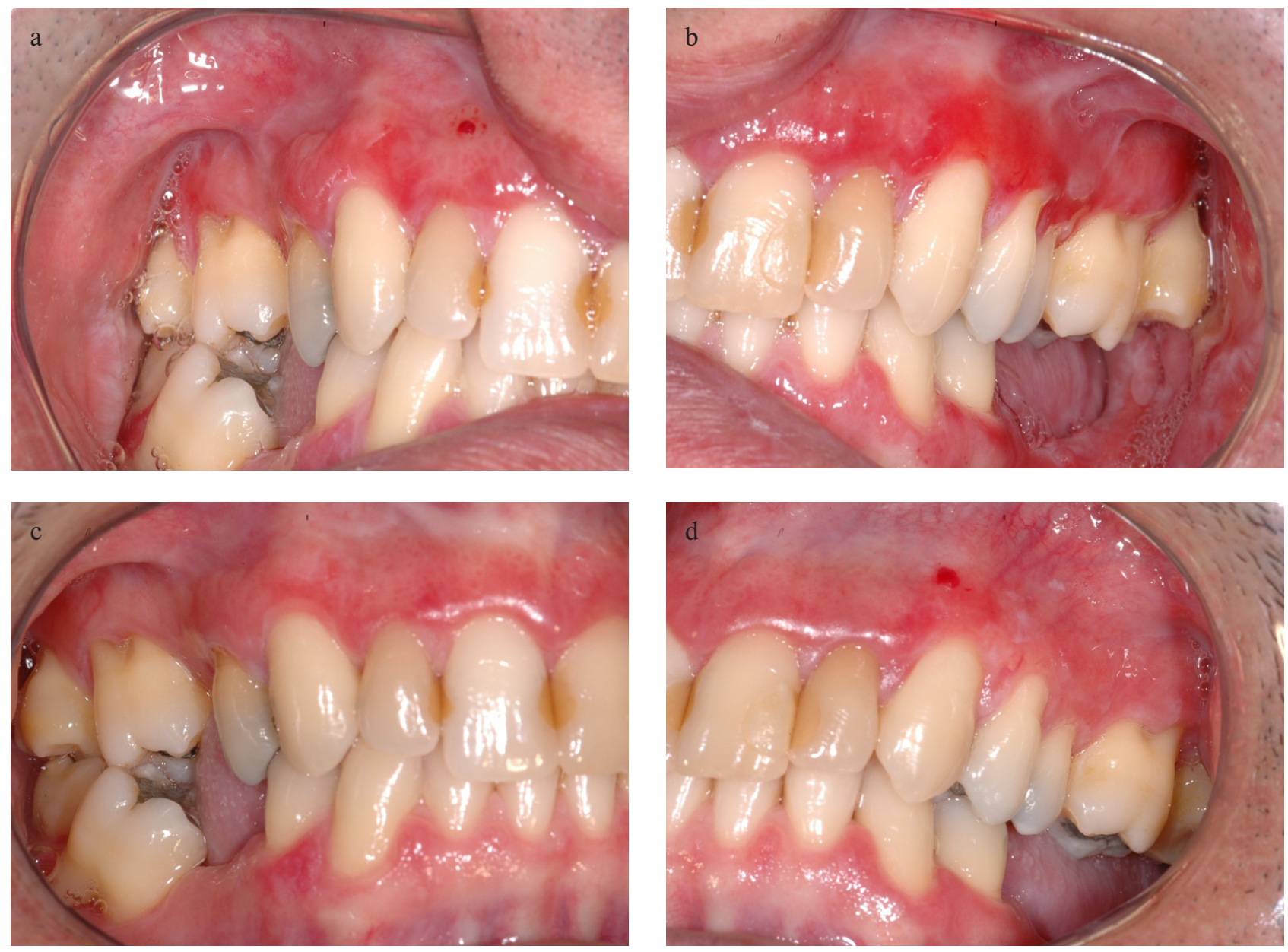

Fig. 1. Clinical aspect of the lichen planus on the upper gum, pre (a, b) and post (c, d) topic gel treatment, one month and half later.

At this time he was referred to the Periodontology Clinic to remove plaque and calculus deposits and to receive good oral hygiene instructions. He was seen weekly till the remission of the gingival lesions, what occurred one month later. Then the patient was instructed to stop using the tray and was scheduled to return at 3 months, but he failed and returned only approximately 7 months later with lesions and symptoms similar to the initial presentation. In this time the therapy was restarted for 4 weeks and 9 months after this period the patient remains symptom free. The patient has been under continuous care (more than 2 years) since the initial presentation.

\section{Case 2}

A 44-year-old healthy white female was referred by her private periodontist to the same Service for evaluation of persistent pain associated soreness of her gums for four years. She was also complaining of gingival burning during her oral hygiene. Intraoral examination revealed severe, extensive and erythemathous desquamative lesions of the gingiva, which were generalized for all maxillar and mandibular teeth, bilaterally (Fig. 2a). Periodontitis was not verified on clinical probing. The patient had good oral hygiene.
Incisional biopsy was carried out and histopathological examination confirmed the diagnosis of atrophic-erosive OLP. The treatment prescribed for the patient was the same described in case 1 . She was seen weekly till the remission of the gingival lesions, what occurred one month and half later. During this period a good healing of gingival lesions was noted with reduction in erythema in some regions and complete resolution of pain (Fig. 2b). She was oriented to stop using the trays and scheduled for a return at 3 months, remaining asymptomatic thoroughout this period.

An outbreak emerged one month after follow-up visit and the therapy was restarted for one month. Two years follow-up shows periodics recurrence, each 4-6 months, with less severe symptoms. The patient reported that acute exacerbations were linked to periods of psychological stress and anxiety. She continues to be on therapy, when clinical symptoms reappear.

\section{DISCUSSION}

The gingiva is a target of autoimmune diseases and about $10 \%$ of patients with OLP have the disease confined 

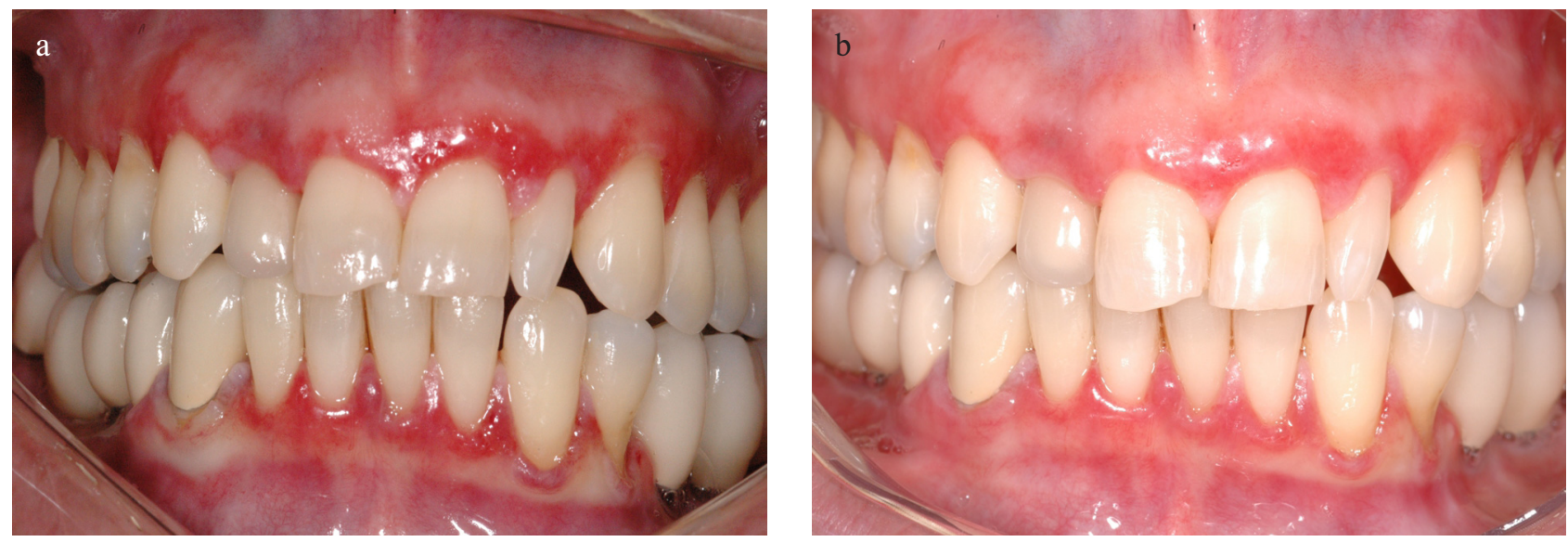

Fig. 2. Clinical aspect of the lichen planus on the upper and lower gums, pre (a) and post (b) topical gel treatment, one month and half later.

to the gingiva, clinically named desquamative gengivitis $(\mathrm{DG})^{2}$. DG can present as reticular, erosive or atrophic subtypes ${ }^{10}$ however, the clinical appearance of DG is not pathognomonic and may represent the gingival manifestation of many others autoimmune diseases ${ }^{10}$. Exacerbations of DG have been associated to periods of psychological stress, anxiety and mechanical trauma. ${ }^{4}$ Chronic low-grade irritation from dental biofilm, calculus, may also cause exacerbation of $\mathrm{DG}^{11}$. The presence of gingivitis and periodontitis can complicate the symptoms of $\mathrm{DG}^{4}$.

Certain local factors including plaque and calculus deposits are associated with a significantly higher incidence of erythemathous and erosive lesions, whereas good oral hygiene is essential and can enhance healing ${ }^{8,11}$. However, the periodontal treatment fails to completely resolve the lesions ${ }^{8}$, maybe due to the immune nature of lichen planus. On the other hand, other authors ${ }^{11}$, suggested in global terms that periodontal status in lichen planus is no worse than that observed among healthy controls, therefore, periodontal attachment loss was found to be very similar in lichen planus patients both with and without gingival involvement. They failed to demonstrate that lichen planus patients have increase long -term risk of periodontal disease.

There is a large amount of available treatments due to recurrence, high prevalency and risk for malignant transformation of oral lichen planus ${ }^{4}$. Anti-inflammatory agents mainly topical corticosteroids are the most widely used in the treatment of OLP ${ }^{12}$. Other therapeutic agents that have been investigated are acitretin, retinoids, imunosuppressants such as cyclosporin, azathioprine, mycophenolate mofetil, tacrolimus and pimecrolimus, thalidomide, interferon alpha, levamisole and phototherapy ${ }^{1}$.

Corticoesteroids suppress cell mediated immune activity $^{2-4,12}$, but therapeutic responsiveness may differ between patients ${ }^{12,13}$. This aside, they can be effectively applied to the lesions with minimal potential for systemic damage.

Previous reports have already shown the effectiveness of clobetasol propionate in the management of OLP ${ }^{13}$. It is the most potent of all topical steroids, exerts antiin- flammatory, immunosuppressive and antimitotic effects influencing the growth, differentiation and function of various cells and inhibiting cytokines ${ }^{14}$. Clobetasol inhibits the production of phospholipase $\mathrm{A}_{2}$ and subproducts as lipooxygenase and ciclooxygenase ${ }^{14}$, this would explain its greater effectiveness.

The application of corticoesteroids by means of a tray in the treatment of severe atrrophic-erosive gingival lesions has already been reported as an efficacious thera$\mathrm{py}^{15}$. The use of trays allows good control over the contact time between the medication and the lesion. Besides, without their use the clinician cannot be sure that the patient will place the medication on all the gingival lesions or that the desired contact time will be maintained.

The pharmaceutic form (gel basis) and the time of adherence enable it to be easily spread over gingival tissues. Furthermore, the topical use may enhance the local drug absorption, improve the anti-inflammatory action of clobetasol and Calendula, not leading to undesirable side-effects. Continuing improvements in topical corticoid formulations aimed at maximizing penetration of the epithelium, will foreseably improve efficacy. However, there are no definitive data to prove that topical antiinflammatory agents in gel bases are more effective than other preparations.

Calendula officinalis $\mathrm{L}$ is a medicinal plant that has bactericide, antiseptic and anti-inflammatory properties ${ }^{16}$. The plant parts used for pharmaceutical and cosmetic purposes are the dried flower heads or the dried ligulate flowers. The ligulate flowers contain triterpene saponins, triterpene alcohols and their fatty acid esters, carotenoids, flavonoids, coumarins, essential oil and hydrocarbons and fatty acids ${ }^{16}$. The herb and pharmaceutical preparations derived from it have been positively reviewed for the promotion of wound healing and as a topical antiinflammatory ${ }^{16}$. Evidence demonstrates that Calendula used in a variety of concentrations might be effective in shortening the duration of wound healing ${ }^{17,18}$.

The anti-inflammatory properties of Calendula flowers have been attributed to the triterpenoid fatty acid esters. 
Of these, the lauryl, myristoyl and palmitoyl esters of faradiol are the most abundant ${ }^{16}$.

After a review of the literature, no reports on the association of Calendula and clobetasol in the treatment of LP were found. A case of recurrent exfoliative cheilitis successfully treated with topical Calendula officinalis $L$ ointment $10 \%$ were reported ${ }^{19}$.

Nystatin was added to the gel basis in order to prevent oral candidosis, one of the most frequent side effects in long term use of corticosteroid therapy ${ }^{5}$; the occlusive nature of the tray method could induce oral candidiasis. Pectin is used as gelling and thickening agent to bind cells together and regulate water. It is also used in wound healing preparations and specialty medical adhesives. It helps to maintain the drug in contact with the gingival mucosa.

Patients with desquamative gengivitis should be monitored throughout life, in view of the chronic nature of this disorder, with frequent reactivations. Control of symptoms, burning sensation to severe pain and functional incapacity in DG is particularly important. The application of this handling gel by means of a tray may be an efficacious treatment of desquamative gingivitis.

In summary, additional studies should be performed to elucidate the pharmacological action of Calendula officinalis $L$ in the management of the desquamative gingivitis, as clobetasol has proven its effectiveness in several studies $^{4-7}$. A study showing the results of a larger group of patients will be provided in future.

\section{CONCLUSION}

The results presented allow the authors to consider the association between clobetasol and Calendula officinalis $L$ as a potential therapy in cases of desquamative gengivitis.

\section{REFERENCES}

1. Agahahosseini F, Arbabi-Kalati F, Fashtami L, Fateh M, Djavid GE. Treatment of oral lichen planus with photodynamic therapy mediated methylene blue: a case report. Med Oral Patol Oral Cir Bucal. 2006;1:26-9.

2. Scully C, Carozzo M. Oral mucosal disease: lichen planus. Br J Oral Maxillofac Surg. 2008;46:15-21.

3. Lodi G, Scully C, Carrozzo M, Griffiths M, Sugerman P B, Thongprasom K. Current controversies in oral lichen planus: Report of an international consensus meeting. Part 1. Viral infections and etiopathogenesis.Oral Surg Oral Med Oral Pathol Oral Radiol Endod. 2005;100:40-51.
4. Ismail SB, Kumar SKS, Zain RB. Oral lichen planus and lichenoid reactions: etiopathogenesis, diagnosis, management, and malignant transformation. J Oral Sciences. 2007;49:89-106.

5. Al-Hashimi I, Schifter M, Lockhart P, Wray D, Brennan M, Migliorati CA et al. Oral lichen planus and oral lichenoid lesions: diagnostic and therapeutic considerations. Oral Surg Oral Med Oral Pathol Oral Radiol Endod. 2007;103:S25.e1-S25.e12.

6. Lodi G, Scully C, Carrozzo M, Griffiths M, Sugerman P B, Thongprasom K. Current controversies in oral lichen planus: Report of an international consensus meeting. Part 2. Clinical management and malignant transformation. Oral Surg Oral Med Oral Pathol Oral Radiol Endod. 2005;100:164-78.

7. Torti DC, Jorizzo JL, McCarty MA. Oral lichen planus. A case series with emphasis on therapy. Arch Dermatol. 2007;143:511-15.

8. Holmstrup P, Schiotz AW, Westergaard J. Effect of dental plaque control on gingival lichen planus. Oral Surg Oral Med Oral Pathol. 1990;69:585-90.

9. Scully C, El Kom. Lichen planus: review and update on pathogenesis. J Oral Pathol. 1985;14:431-58.

10. Mignona MD, Lo Russo L, Fedele S. Gingival involvement of oral lichen planus in a series of 700 patients. J Clin Periodontol. 2005;32:1029-33.

11. Ramon-Fluixá C, Bagan-Sebastian J, Milian MM, Scully C. Periodontal status in patients with oral lichen planus: a study of 90 cases. Oral Dis. 1999;5:303-6.

12. Carbone M, Goss E, Carrozo M, Castellano S, Conrotto D, Broccoletti R et al. Systemic and topical corticosteroid treatment of oral lichen planus: a comparative study with long term follow-up. J Oral Pathol Med. 2003;2:323-9.

13. Corrocher G, Di Lorenzo G, Martinelli N, Mansueto P, Biasi D, Nocini PF et al. Comparative effect of tacrolimus $0,1 \%$ ointment and clobetasol $0,05 \%$ ointment in patients with oral lichen planus. J Clin Periodontol 2008;35:244-249.

14. Pels R, Sterry W, Lademann J. Clobetasol propionate-where, when, why? Drugs Today (Barc). 2008;44:547-57.

15. Gonzalez-Moles MA, Ruiz-Avila I, Rodriguez-Archilla A, MoralesGarcia P, Mesa-Aguado F, Bascones-Martinez A et al. Treatment of severe erosive gingival lesions by topical application of clobetasol propionate in custom trays. Oral Surg Oral Med Oral Pathol Oral Radiol Endod. 2003;95:688-92.

16. Hamburger M, Adler S, Baumann D, Förg A, Weinreich B. Preparative purification of the major anti-inflammatory triterpenoid esters from Marigold (Calendula officinalis). Fitoterapia. 2003;74:328-338.

17. Perri de Carvalho PS, Tagliavini DG, Tagliavini RL. Cutaneous cicatrization after topic application of calendula cream and comfrey, propolis and honey association in infected wound of skin. Revista Ciência Biomédica. 1991;12:39-50.

18. Lievre M, Marichy J, Baux S, Foyatier JL, Perrot J, Bossel JP. Controlled study of the three ointments for the local management of $2^{\text {nd }}$ and $3^{\text {rd }}$ degree burns. Clinical Trials and Meta Analisys. 1992;28:9-12.

19. Roveroni-Favaretto LH, Lodi KB, Almeida JD. Topical Calendula officinalis L. successfully treated exfoliative cheilitis: a case report. Cases J. 2009;23:9077. 